\title{
Major congenital malformations of foetus: a bane in pregnancy
}

\author{
D. M. Christe ${ }^{1 *}$, D. Mohana ${ }^{2}$, S. Shobha ${ }^{2}$
}

\begin{abstract}
${ }^{1}$ Department of Research in Human Reproduction, Institute of Obstetrics and Gynecology, National Institute for Research in Human Reproduction-Field Unit, Indian Council of Medical Research, Chennai, Tamil Nadu, India ${ }^{2}$ Department of Obstetrics and Gynecology, Institute of Obstetrics and Gynecology, Chennai, Tamil Nadu, India
\end{abstract}

Received: 20 August 2020

Revised: 29 September 2020

Accepted: 30 September 2020

\author{
*Correspondence: \\ Dr. D. M. Christe, \\ E-mail: cdmone23@gmail.com
}

Copyright: (C) the author(s), publisher and licensee Medip Academy. This is an open-access article distributed under the terms of the Creative Commons Attribution Non-Commercial License, which permits unrestricted non-commercial use, distribution, and reproduction in any medium, provided the original work is properly cited.

\section{ABSTRACT}

Background: The aim of the study was to find out the numbers of women presenting with pregnancy complicating with major congenital anomalies of the fetus.

Methods: This study was conducted over a period of fifteen months in the year 2018-2019. The types of congenital anomalies were that of the central nervous system, cardiac, renal, gastrointestinal, skeleto-muscular, hydrops foetalis, chromosomal, single umbilical artery and other multiple anomalies. Other variables regarding the age group of the mother, gravida, parity and gestational age at which the pregnancy was terminated was also noted.

Results: A total of 212 pregnancies were diagnosed with major congenital anomalies of fetus and opted for termination. Malformations of the central nervous system (CNS) of fetus, formed the largest group of 56.6\%, and fetal gastrointestinal malformations and fetal renal anomalies occupied the second major groups forming $11.8 \%$ and $11.3 \%$ respectively. The age group of women ranged between 23 years to 38 years. The largest group of pregnant women with fetal malformations were aged between 23-27 years. Primigravida with zero parity women were $60.4 \%$ of the total group of women with major fetal anomalies.

Conclusions: Maximum number of congenital anomalies were seen in primigravida and para one mothers. Genetic counseling should be offered for women at clinics, before planning further pregnancy. Facilities should be made available for poor people from remote areas for early detection of congenital anomalies.

Keywords: Congenital malformation, Fetus, Pregnancy

\section{INTRODUCTION}

Congenital anomalies are birth defects, which could be structural or functional anomalies that occur during the intrauterine life. They can be identified prenatally at birth, or sometimes may be detected only later in infancy, such as hearing defects. An estimated 30300 new-borns die within 4 weeks of birth every year worldwide due to congenital anomalies. ${ }^{1}$

In a recent study in India, among 1822 births, the total prevalence of major congenital anomalies was 230.51 per 10000 births. $^{2}$ Congenital anomalies of poor prognosis are defects in the foetus that are incompatible with life outside the womb, and usually it is observed that these pregnancies end in intrauterine death or the baby dies immediately after birth. The parents usually request for termination of pregnancy. These congenital anomalies include anencephaly, severe pulmonary hypoplasia, a cardiac foetus, cervical ectopia cordis, and non-mosaic trisomy. ${ }^{3}$ The study was conducted in a public tertiary referral centre for obstetric care and a teaching hospital in Chennai, India.

\section{Ethical clearance}

This was a retrospective analytical study. Approval for conducting this study was given by the Institutional Ethics 
Committee, Institute of Obstetrics and Gynecology. Consent was not obtained from individual study participants as data was accessed from medical records only and was analyzed maintaining complete patient confidentiality.

The aim of the study was to find out the numbers of women presenting with pregnancy complicating with major congenital anomalies of the fetus.

\section{METHODS}

This study was conducted in the Institute of Obstetrics and Gynecology, Chennai, over a period of fifteen months in the year 2018-2019. The total number of pregnancies with congenital anomalies of the foetus was obtained from the special reports maintained for termination of pregnancies with congenital anomalies for a period of 15 months from the month of January in the year 2018 till the month of April in the following year 2019. The special record maintained for pregnancy with complicating major congenital anomalies was accessed. The nature of these Congenital anomalies was that there was a poor prognosis for the defects in the foetus namely that they were incompatible with life outside the womb, and usually these pregnancies ended in intrauterine death or the baby would die immediately after birth, and facilities for corrective surgery for the anomaly was not available or affordable in the institution The mother had the choice to opt for termination as allowed by the existing rules under the law.

The types of congenital anomalies were classified under the headings of central nervous system, cardiac, renal, gastrointestinal, skeleto-muscular, hydrops foetalis, chromosomal, respiratory, single umbilical artery and other multiple anomalies. Other variables regarding the age group of the mother, gravida, parity and gestational age at which the pregnancy was terminated was also noted. Statistical analysis was done using standard formulae, using Microsoft excel.

\section{RESULTS}

A total of 212 pregnancies were diagnosed with major congenital anomalies. There was a total of 19311 deliveries in the study period. As the expected outcome of pregnancy was poor for foetus either intrauterine demise or death shortly after birth all these women had requested for termination of pregnancy.

Women with malformations of central nervous system (CNS) of fetus, formed the largest group of $56.6 \%$ of the total group of pregnant women with major malformations in the fetus. Pregnant women diagnosed with fetal gastrointestinal malformations and fetal renal anomalies occupied the second major groups forming $11.8 \%$ and $11.3 \%$ of the total group of women. Of the 212 terminations of pregnancy done for major fetal malformations, $5.7 \%$ of $(n=12)$ of the foetuses had multiple defects involving more than one system (Figure 1). Hydrops fetalis was detected in $5.2 \%$ of fetuses.

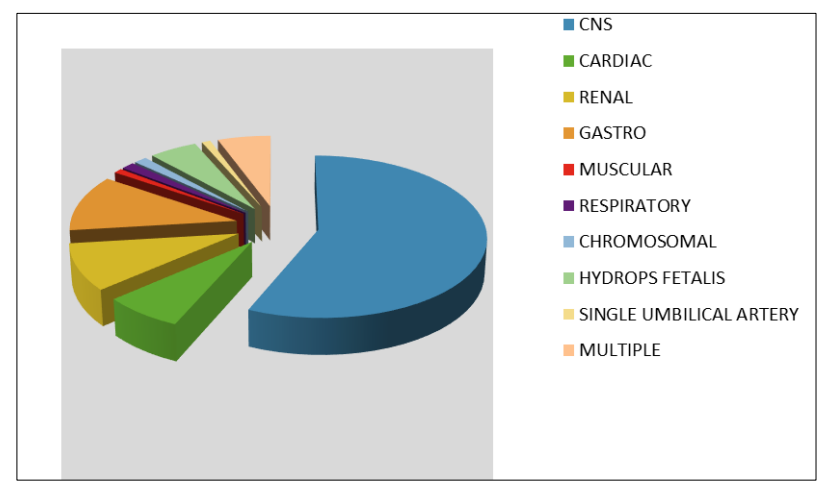

Figure 1: The types of various congenital anomalies of fetus.

The age group of women who presented with pregnancy complicated with major congenital anomalies of foetus ranged between 23 years to 38 years. The largest group of women with major anomalies of foetus were young and were in the age group between 23-27 years. The second largest group of women were also in the younger age group and their ages ranged between 18 years to 22 years. A small percentage of $1.4 \%$ of women $(n=3)$ were aged between 37 years and 38 years (Figure 2).

Most of the women who with fetal malformation were in the age group of 23-27 years.18-22 years age group formed the second largest group in this study population. Women aged 37 years to 38 years formed a small of $1.4 \%$ of the total study group (Figure 2).

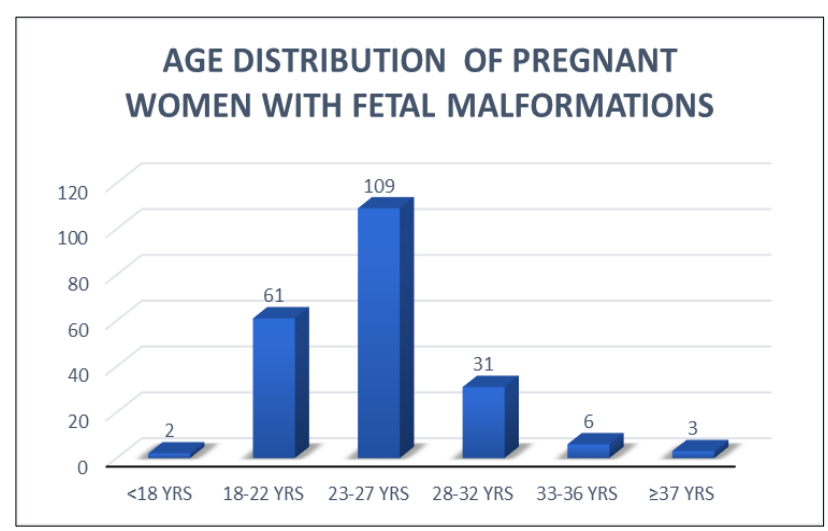

Figure 2: The largest group of pregnant women with major anomalies of foetus were aged between 23 and 27 years.

It was important to note that the largest group requesting for termination of pregnancy for congenital anomaly of foetus were gravida one women. This group of gravida one women were twice the number of gravida two women with congenital anomalies detected in foetus, and four times the number of gravida three women with foetal anomalies. 
Figure 2 shows that the largest group of pregnant women with major anomalies of foetus were aged between 23 and 27 years.

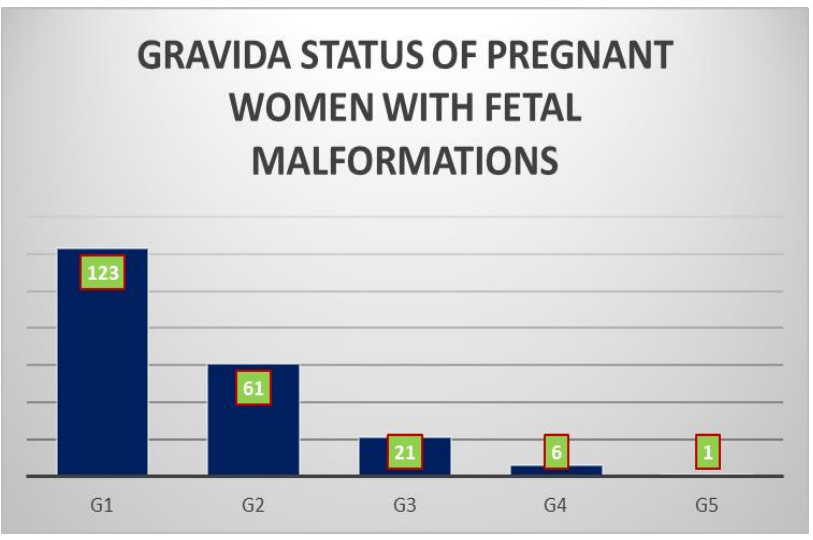

Figure 3: Gravida status of the pregnant women with fetal malformations.

Figure 3 shows gravida 1 women formed the largest group. A small group of gravida four and gravida five pregnant women had complicated major anomalies of fetus.

Gravida 1 women formed the largest group of $58 \%$ of women with major congenital anomalies in the foetus. This group was twice as large as the group of gravida 2 women $(28.8 \%)$ with fetal anomalies. The group of gravida 3 women $(9.9 \%)$ who had major anomalies of fetus complicating of pregnancy were only one-fourth of gravida 1. Gravida 4 and 5 formed a small part of the total group. The largest number of women who requested for termination of pregnancy because of major anomalies of the fetus underwent termination of pregnancy between 20 to 23 weeks of gestation.

\section{DISCUSSION}

Most congenital anomalies are detected only after 20 weeks because of the lack of high-resolution ultrasound and other tests for detection of anomalies at most health centers. The nature of the congenital anomaly is only detected by high resolution ultrasound and another test. ${ }^{4-6}$ Only these tests can provide information regarding the viability of the foetus after birth. Antenatal surgical interventional feasibility has become a possibility now for some anomalies. ${ }^{7}$ Such facilities are available in very few centres. ${ }^{8}$ The cost is high and the risk of survival of the baby still remains remote. These factors have to be considered and viability of the fetus should be determined, and all risks be informed to the mother who can be reassured to continue the pregnancy. Such facilities are not available in most places and a very few anomalies can be surgically corrected antenatally and even fewer centers offer such facilities. ${ }^{9}$

In one such incidence where the diagnosis of anencephaly was done late in pregnancy and the mother was denied termination of pregnancy because of the existing abortion laws. The United Nations human rights committee (HRC) which concluded that to carry the pregnancy with the anencephalic baby to term, and nurse the baby for few days before its demise, amounted to cruel and inhuman punishment in violation of article 7 of the International covenant on civil and political rights. ${ }^{5}$ The American college of obstetricians and gynecologists (ACOG) guidelines states, circumstances that in rare situations beyond 20 weeks of gestation termination may still be permitted. This is because of delays in suspecting and testing for pregnancy, delay in obtaining insurance or other funding, and delay in obtaining referral, as well as difficulties in locating and traveling to a provider, leads to delay in diagnosis of fetal malformations.

Congenital anomalies can be terminated up to 20 weeks of gestation by medical termination of pregnancy according to the medical termination of pregnancy (MTP) act of 1971. Poverty, lack of awareness, and having multiple disruptive life events, have been associated with higher rates of seeking second-trimester abortion In addition, major anatomic or genetic anomalies may be detected in the foetus in the second trimester and women may choose to terminate their pregnancies $(47-95 \%) .{ }^{10-13}$

Poverty, lack of awareness and having no means to find out the health of the foetus and therefore unable to recognize congenital abnormalities till late in pregnancy and at times only in the third trimester. This is a problem which is encountered many times and is of concern to both the mother and the caregiver. Some such mothers are able to seek termination of pregnancy very late in the second or third trimester only, for the causes mentioned above. ${ }^{14}$

The spectrum and incidence of congenital heart disease detected in early pregnancy and mid-pregnancy screening are different. ${ }^{15-17}$ Early pregnancy screening has an important impact on the outcome of a foetus with congenital heart disease, because at this stage, severe heart malformations, chromosomal abnormalities, and more complications are more likely to be discovered, resulting in more termination of pregnancy in early pregnancy. Some studies also confirm that the types and incidence of cardiac malformations screened in early pregnancy and mid-pregnancy are also inconsistent. The reason is because in the early pregnancy, the incidence of severe congenital heart disease is higher, and often accompanied by other system abnormalities, eventually leading to an increased probability of intrauterine death.

An important and necessary recommendation would be for genetic counseling which will prepare the mother to understand and what risks may be anticipated in future pregnancies. Provision should be made to make folic acid available for at least a year prior to pregnancy for women planning pregnancy later as it prevents neural tube malformations in the fetus. Facilities should be made available for poor people from remote areas for early detection of congenital anomalies, and facilities for safe termination should be provided. 
On viewing the parity of women with anomalous fetuses, the majority of women forming $60.4 \%$ of the total group of women were primigravid with zero parity. Para one women formed $31.6 \%$ and $7.6 \%$ of women were para two. The highest parity observed was para three which was less than $0.5 \%$ of the total group. Fetal malformations are seen in 3 to $5 \%$ of all pregnancies. Early detection of malformation of the fetus has improved because of ultrasound imaging technology. In most middle-income countries, a second trimester scan between 18 and 22 weeks gives the more accurate picture wherein a diagnosis of fetal anomalies by assessment of the structure of the fetus can be made with certainty.

Figure 4 shows the maximum number of congenital anomalies were seen in primigravida and para one mothers, and in the age group of 23 to 27 years.

In many pregnancies the anomalies of the fetuses are detected between the gestational ages of 12 to 16 weeks. A large number of women had requested to terminate the pregnancy before the congenital anomalies were terminated before 16 weeks. ${ }^{18}$ Yet often clear proof of major anomaly of fetus is possible only after 16 to 19 weeks of gestation which was seen in our study where the largest number of women who requested for termination of pregnancy because of major anomalies of fetus underwent termination of pregnancy between 20 to 23 weeks, because of various other parameters which are involved before termination could be done (Figure 4).

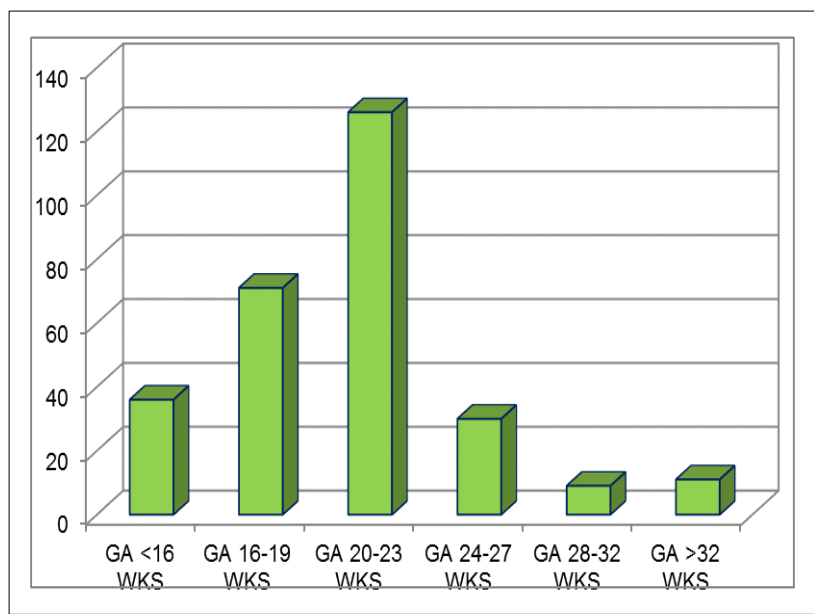

Figure 4: Gestational ages of pregnancy at the time of diagnosis of fetal malformation.

The centre being a tertiary referral centre with facilities for high resolution ultrasound scan, it was observed that almost seventy percent of women had termination of pregnancy prior to twenty weeks of gestation. As many women had to come from far off places and rural areas, and the diagnosis of malformation of fetus is done around twenty weeks of gestation, it was observed that a significant number of women opted for termination after completion of twenty weeks of gestation. ${ }^{19}$

\section{CONCLUSION}

A pregnant woman when diagnosed with major malformation of fetus suffers much agony, along with her family. The maximum number of congenital anomalies were seen in primigravida and para one mothers, and in the age group of 23 to 27 years. In many women diagnosis of the congenital anomalies is only after 20 weeks of gestation

\section{Recommendations}

An important and necessary recommendation would be for genetic counseling which will prepare the mother to understand and what risks may be anticipated in future pregnancies. Provision should be made to make folic acid available for at least a year prior to pregnancy for women planning pregnancy later as it prevents neural tube malformations in the fetus. Facilities should be made available for poor people from remote areas for early detection of congenital anomalies, and facilities for safe termination should be provided.

\section{ACKNOWLEDGMENTS}

Authors would like to thank all the staff, in their centre who lent their support in preparing this article.

Funding: No funding sources

Conflict of interest: None declared

Ethical approval: The study was approved by the Institutional Ethics Committee

\section{REFERENCES}

1. World Health Organization. Fact Sheet .Congenital Anomalies. 2016. Available at: https://www.who.int/news-room/factsheets/detail/cogenital-anomalies. Accessed on: 13 November 2019.

2. Cortés F, Faundes V, Mellado C, Passalacqua C. Congenital anomalies of poor prognosis. Genetics Consensus Committee. Medicine. 2019;98(33):16822.

3. P.Bhide and A.Kar A national estimate of the birth prevalence of congenital anomalies in India: systematic review and meta-analysis. BMC Pediatr. 2018; 18: 175. doi: 10.1186/s12887-018-1149-0

4. Incidence of congenital anomalies in a rural population of Jammu - A prospective study A. Anjum, K. Dinesh, D. Deepika, D.Nasib C .: 2018 | Vol.: 62 | Iss.: 3 | Page: 188-192.

5. Kosinski P, Brawura Biskupski Samaha R, Lipa M, Wielgos M, Kohl T. Contemporary management of prenatally diagnosed spina bifida aperta - an update. Ginekol Pol. 2018;89(11):637-41.

6. Conner P, Vejde JH, Burgos CM. Accuracy and impact of prenatal diagnosis in infants with omphalocele. Pediatr Surg Int. 2018;34(6):629-33. 
7. Boyle B, Addor MC, Arriola L, Barisic I. Estimating Global Burden of Disease due to congenital anomaly. Arch Dis Child Fetal Neonatal Ed. 2018;103(1):22-8.

8. Darlison MW, Modell B. Estimates of global and regional prevalence of neural tube defects for 2015. Ann N Y Acad Sci. 2018;1414(1):31-46.

9. de Groot-van der Mooren MD, Tamminga S, Oepkes D, Weijerman ME, Cornel MC. Older mothers and increased impact of prenatal screening: stable livebirth prevalence of trisomy 21 in the Netherlands for the period 2000-2013. Eur J Hum Genet. 2018;26(2):157-65.

10. The American College of Obstetricians and Gynecologists. Practice Bulletin Second-Trimester Abortion. Obstet Gynaecol. 2013;121(6):1394-406.

11. Chima SC, Mamdoo F. Ethical and legal dilemmas around termination of pregnancy for severe fetal anomalies: A review of two African neonates presenting with ventriculomegaly and holoprosencephaly. Niger J Clin Pract. 2015;18:31-9.

12. Svenaeus F. Phenomenology of pregnancy and the ethics of abortion .The phen Med Health Care Philos. 2018;21(1):77-87.

13. Bing H, Ying L, Yi T, Xueling Q. Clinical analysis of prenatal ultrasound diagnosis of fetal cardiovascular malformations in the first and second trimesters of pregnancy. Medicine. 2019;98(33):16822.

14. Kamranpour B, Noroozi M, Bahrami M. Supportive needs of women who have experienced pregnancy termination due to fetal abnormalities: a qualitative study from the perspective of women, men and healthcare providers in Iran. BMC Public Health. 2019;19:507.

15. Jortveit J, Wik G, Odegaard JS, Sitras V. Diagnosis of severe congenital heart defects in Norway 2016.Tidsskr Nor Laegeforen. 2019;139(2).

16. Bhide P, Gund P, Kar A. Prevalence of Congenital Anomalies in an Indian Maternal Cohort: Healthcare, Prevention, and Surveillance Implications. PLoS One. 2016;10(11):0166408.

17. Marginean C, Sasarean V, Marginean CO. Prenatal diagnosis of cleft lip and cleft lip palate. Med Ultrason. 2018;20(4):531-5.

18. Hill M, Barrett A, Choolani M. Has noninvasive prenatal testing impacted termination of pregnancy and live birth rates of infants with Down syndrome? Prenat Diagn. 2017;37(13):1281-90.

19. Kashyap N, Pradhan M, Singh N, Yadav S. Early Detection of Fetal Malformation, A Long Distance Yet to Cover! Present Status and Potential of First Trimester Ultrasonography in Detection of Fetal Congenital Malformation in a Developing Country: Experience at a Tertiary Care Centre in India. J Pregnancy. 2015;623059.

Cite this article as: Christe DM, Mohana D, Shobha S. Major congenital malformations of foetus: a bane in pregnancy. Int J Reprod Contracept Obstet Gynecol 2020;9:4521-5. 